\title{
TRANSFORMASI BUDAYA BUANG SAMPAH TERPILAH DI PONDOK PESANTREN AL IKHSAN II, BENTOK
}

\author{
Muhammad Saukani*, Jainal Arifin \\ Program Studi Teknik Mesin, Universitas Islam Kalimantan MAB \\ Jl. Adhyaksa NO. 2, Banjarmasin, Kalimantan Selatan, Indonesia \\ saukani@uniska-bjm.ac.id \\ Program Studi Teknik Mesin, Universitas Islam Kalimantan MAB \\ Jl. Adhyaksa NO. 2, Banjarmasin, Kalimantan Selatan, Indonesia \\ jainalarifin804@gmail.com
}

Artikel diterima: 22-03-2019, direvisi: 05-04-2019, diterbitkan: 12-05-2019

\begin{abstract}
Abstrak
Pelatihan dan simulasi buang sampah terpilah telah dilakukan pada santri di Pondok Pesantren Al-Ikhsan II Bentok. Tujuan utama yang ingin dicapai dalam program ini adalah menciptakan budaya buang sampah terpilah, sehingga realisasi pemanfaatan sampah berdasarkan klasternya semakin mudah dilaksanakan. Langkah yang telah dilakukan untuk mencapai tujuan program ini adalah dengan memberikan pengetahuan klasterisasi sampah, dan pemanfaatan sampah menjadi produk yang bermanfaat melalui metode ceramah dan diskusi. Selanjutnya dilaksanakan simulasi buang sampah terpilah oleh peserta program pada tempeh sampah yang telah dihibahkan oleh tim pengusul. Hasil program ini menunjukkan adanya peningkatan pengetahuan peserta program terutama dalam hal pengelolaan sampah anorganik hingga 92\%, dan hasil simulasi menunjukkan bahwa seluruh peserta telah mampu mengklasterisasi sampah berdasarkan tempat sampah yang telah disediakan. Namun hasil evaluasi melalui monitoring tempat sampah terpilah selama 4 minggu menunjukkan bahwa budaya buang sampah terpilah masih belum berhasil, hal ini ditandai dengan tercampurnya antara sampah organik dan organik pada evaluasi minggu ketiga.

Kata Kunci: Sampah, Organik, Anorganik, Terpilah
\end{abstract}

\section{Pendahuluan}

Sampah merupakan masalah klasik lingkungan yang hingga saat ini belum bisa teratasi secara menyeluruh. Permasalahan ini sangat terasa, terutama di Perkotaan dimana semakin banyak jumlah penduduk dengan aktivitasnya maka semakin banyak pula sampah yang dihasilkan. Pada tahun 2012 Kementerian Lingkungan Hidup merilis perhitungan bahwa rata-rata penduduk Indonesia menghasilkan sampah $\pm 0,8 \mathrm{~kg}$ per orang per hari. Untuk itulah, tanpa pengelolaan yang serius, daya dukung lingkungan akan keberadaan sampah akan menjadi semakin buruk.

Sampah mempunyai peranan yang sangat besar dalam terjadinya proses penularan penyakit apabila tidak dikelola dengan baik. Untuk itu perlu pengelolaan yang baik dan ramah lingkungan agar dapat menghindari dampak negatif dari sampah tersebut. Sampah dikelompokkan menjadi dua, yaitu sampah kering (anorganik) dan sampah basah (organik). Sampah kering (anorganik) adalah sampah yang pada umumnya bersifat sulit 
mengurai/membusuk contohnya seperti organik, kaca, dan bahan sterofom. Sebaliknya sampah basah (organik) merupakan sampah yang mudah mengurai membusuk yang terdegradasi oleh bakteri pengurai (Suwahyono, 2014).

Pondok Pesantren Al-Ikhsan II adalah Pondok Pesantren yang memiliki program pembelajaran Tahfidzh Al-Quran Wa AdDa'wah. Pondok Pesantren ini berdiri diatas tanah dengan luas 10 ha. Jumlah santri putra yang belajar di pondok tersebut sejumlah 200 orang yang berasal dari berbagai daerah. Santri yang belajar di pondok pesantren ini dimulai sejak tamat SD.

Sampah yang dihasilkan dari aktivitas santri di pondok pesantren ini belum dilakukan pengelolaan. Jika sesuai dengan perhitungan kementerian lingkungan hidup, maka santri putera akan menghasilkan 160 kg sampah perhari. Sampah organik dan non organik ditumpuk dalam satu wadah tanpa adanya proses pemisahan. Sampah yang telah terkumpul dalam bak sampah ditumpuk dalam lubang pembuangan dan kemudian dibakar.

Penanganan sampah dengan metode penumpukan dan kemudian dibakar. Metode ini dipilih karena berbagai alasan diantaranya tidak ada fasilitas mobil angkut sampah ke TPS lahan penumpukan sampah tersedia sangat luas sehingga peningkatan volume sampah yang masuk dan diimbangi dengan proses pembakaran seakan-akan masalah sampah telah selesai.
Cara penyelesaian sampah dengan metode timbun dan bakar bukanlah sebuah solusi yang tepat (Pane, 2013). Hal ini akan berdampak pada kualitas lingkungan yang akan semakin memburuk baik keadaan tanah yang akan tercemari lindi (Yatim \& Mukhlis, 2013) dan udara yang akan tercemari $\mathrm{CO}_{2}$ bahkan senyawa dioksin, senyawa yang dapat memicu pembengkakan hati, kanker, dan asma jika terhirup oleh manusia (Norsujianto, 2015). Pengabdian masyarakat inilah merupakan salah satu langkah awal yang tepat untuk mengajak para santri agar lebih peduli terhadap lingkungan pondok pesantren. Jumlah santri yang masih sedikit, memudahkan tim pelaksana untuk melakukan pendekatan secara persuasif, mengkampanyekan kesadaran akan pemilahan sampah, sehingga santri memiliki modal pengetahuan tentang edukasi pengelolaan sampah yang ramah lingkungan.

\section{Metode Pelaksanaan Kegiatan}

Tujuan dilaksanakan program ini adalah terciptanya budaya uang sampah secara terpilah, sehingga untuk pemanfaatan sampah berikutnya akan lebih mudah. Untuk mencapai tujuan tersebut maka metode pendekatan yang gunakan adalah Metode ceramah, Metode Tanya jawab (diskusi) dan Metode partisipatif dan simulasi.

Adapun beberapa kegiatan yang dilaksanakan dalam program ini adalah:

1. Pembuatan Tempat Sampah Tepat Guna oleh Tim. 
2. Memberikan sosialisasi pengelolaan sampah dan kepedulian kesehatan lingkungan.

3. Simulasi pembungan sampah secara terpilah oleh khalayak.

4. Evaluasi

Khalayak sasaran yang menjadi objek program ini adalah santri di Pondok Pesantren Tahfidzul Quran wa dakwah AlIkhsan II Bentok. Jumlah seluruh peserta program pengabdian ini adalah 46 orang santri dengan jenjang kelas yang berbeda.

\section{Hasil PelaksanaAn Kegiatan}

\section{Persiapan Bak Sampah Terpilah}

Keberhasilan pengelolaan sampah ditentukan penanganan awal dilakukan terhadap sampah tersebut. Bercampurnya sampah organik dan anorganik membuat sampah tidak bisa dimanfaatkan kembali menjadi produk sisa yang berguna. Slogan "Membuang sampah pada tempatnya" masih belum cukup untuk menciptakan lingkungan yang bersih, karena dengan sampah yang tercampur cara instan untuk mereduksinya adalah dengan cara membakar. Perilaku ini tentunya akan menimbulkan masalah baru bagi lingkungan.

Langkah awal untuk membangun budaya sampah terpilah diupayakan tim pengabdian masyarakat dengan menghibahkan bak sampah terpilah kepada khalayak sasaran. Bak sampah ini terbuat dari drum bekas yang dimodifikasi dan dilapis dengan cat serta diberi label antara tempat sampah organik dan anorganik. Adapun kegiatan persiapan pembuatan bak sampah ini disajikan pada gambar 1a. Bak sampah terpilah yang siap dihibahkan kepada khalayak sasaran disajikan pada gambar $1 \mathrm{~b}$.

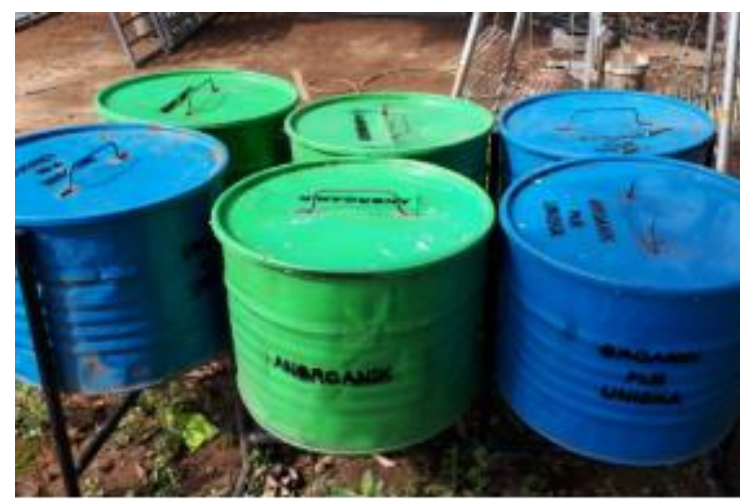

(a)

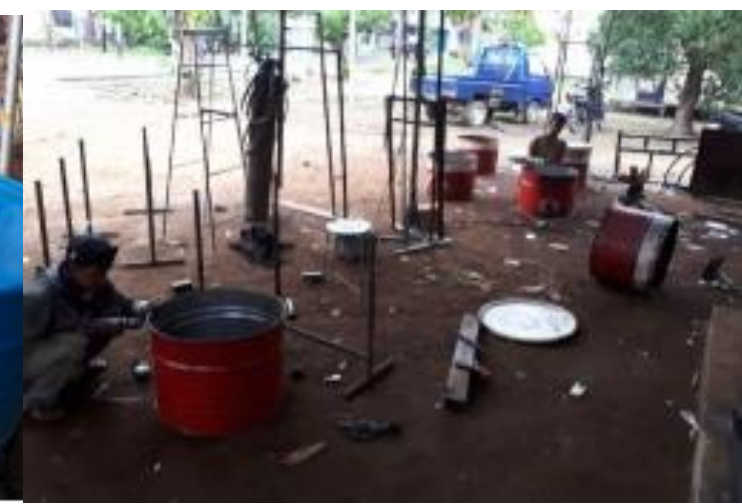

(b)

Gambar 1. (a) Tahapan persiapan pembuatan Bak sampah terpilah, (b) Bak sampah terpilah

\section{Sosialisasi}

Pelaksanaan sosialisasi dilaksanakan di Ponpes Al-Ikhsan II Putra, pada tanggal 26 Januari 2018. Kegiatan ini diikuti oleh 46 orang santri baik santri tahfidz maupun santri kitab. Materi sosialisasi menjelaskan pengertian sampah, komposisi sampah (organik dan nonorganik), paradikma baru penelolaan sampah, pemanfaatan sampah organik dan non organik, penayangan 
video pembuatan bahan bakar dari destilasi sampah organik. Suasana sosialisasi pengelolaan sampah disajikan pada gambar 2 .

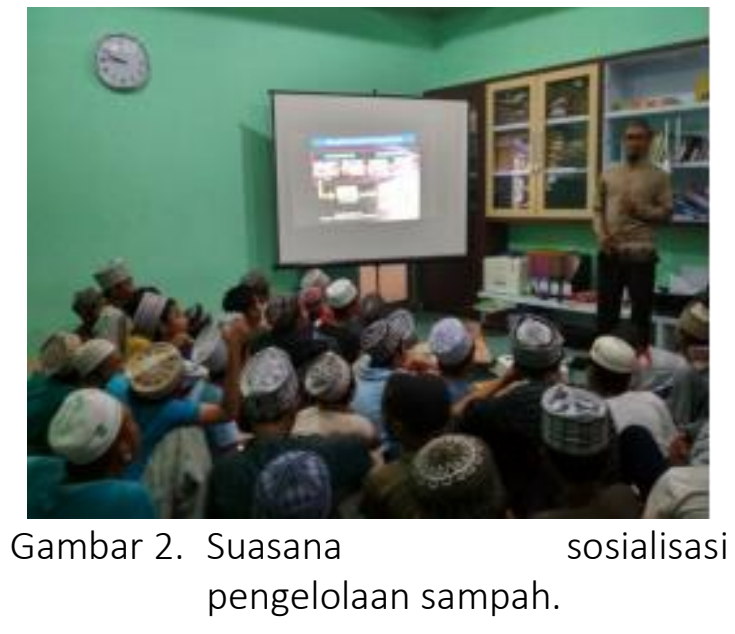

Sosialisasi ini sangat menekankan pengetahuan pada perbedaan sampah organik dan anorganik, beberapa pertanyaan peserta dengan menyebutkan contoh sampah dan termasuk dalam golongan apa. Terdapat kendala saat sosialisasi, dimana yang dihadapi adalah peserta dengan usia 13-16 tahun dengan latar pendidikan lulusan SD, untuk itu perlu kesabaran untuk dapat masuk kepada psikologi mereka (Pane, 2013).

Secara teoritis, pemanfaatan sampah organik dan non organik mereka telah mengetahui, namun bagaimana teknisnya masih belum pernah dipraktikkan. Penggunaan sampah organik digunakan sebagai kompos dan pupuk cair (Wahyuningsih \& Supriyo, 2013). Sampah organik dari bungkus makanan kemasan bisa digunakan sebagai kerajinan tangan, botol bekas dapat dimanfaatkan untuk vas bunga, dan berbagai wadah olahan lainnya (Putra \& Yuriandala, 2010).

Pengetahuan baru buat mereka tentang pemanfaatan sampah nonorganik lainnya yang banyak digunakan oleh masyarakat terutama styrofoam dan organik HDPE. Dalam sosialisasi ini di tayangkan video destilasi sampah organik yang tidak dapat didaur ulang ternyata dapat digunakan kembali sebagai bahan bakar cair. Begitu pula sampah Styrofoam yang dapat dimanfaatkan sebagai filler bata ringan. Sosialisasi ini memberikan kontribusi berupa penambahan wawasan bagi khalayak sasaran.

\section{Simulasi}

Simulasi pembuangan sampah secara terpilah oleh santri dilaksanakan setelah pelatihan selesai dilaksanakan. Masingmasing santri diberikan kotak konsumsi berisi snack yang outputnya adalah sampah organik dan anorganik. Hasil pengamatan langsung saat simulasi ini dilaksanakan, seluruh peserta dapat menempatkan sampah pada tempat sampah berdasarkan klasifikasinya.

Agar tempat sampah memberi manfaat bagi instansi sasaran maka penempatannya sasaran penempatannya diatur berdasarkan frekuensi kunjungan santri dan potensi penghasil sampah. Tempat sampah terpilah diletakkan di depan kantor pondok, kantin dan dapur. Pemantauan keberhasilan program dievaluasi satu bulan kemudian. Adapun jumlah tempat sampah terpilah yang 
dihibahkan kepada khalak berjumlah 3 pasang.

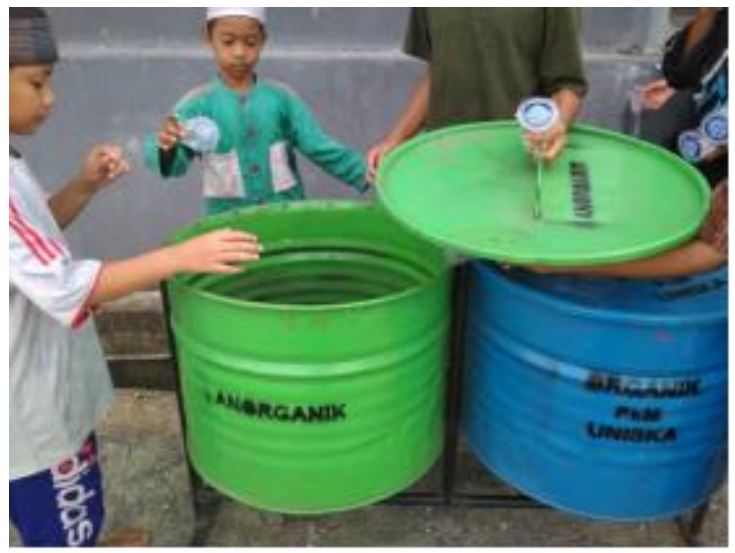

Gambar 3. Simulasi Pembuangan sampah

\section{Evaluasi}

Evaluasi dilaksanakan selama empat minggu dengan pemantauan tumpukan sampah setiap hari minggu. Hasil evaluasi dilapangan mengindikasikan bahwa tidak adanya perubahan perilaku khalayak sasaran dalam membuang sampah. Meskipun sudah dipisahkan antara tempat sampah organik dan anorganik, namun isi dari bak sampah belum sesuai dengan harapan misalkan bungkus makanan berupa daun dicampur dengan botol minuman yang terbuat dari plastik. Sampah diletakkan sesuai kategorinya hanya berlaku hingga minggu kedua, selebihnya kembali pada keadaan semula.

\section{Kesimpulan}

Program Pengabdian Masyarakat yang diberikan kepada Santri Ponpes Al-Ikhsan Putra, Bentok yang dimulai dengan persiapan tempat sampah terpilah, pemaparan materi manajemen sampah dan pemanfaatannya, simulasi pembuangan sampah secara terpilah dan evaluasi perubahan budaya buang sampah terpilah. Kesimpulan dari kegiatan ini adalah sebagai berikut:

1. Materi pelatihan terutama untuk klasterisasi sampah organik dan anorganik dipahami oleh santri dengan baik yang terbukti dengan tepatnya peletakan sampah saat simulasi dilakukan

2. Santri mendapatkan pengetahuan baru dalam pemanfaatan sampah organik HDPE dan Styrofoam.

3. Hasil evaluasi setelah program dilaksanakan menunjukkan belum adanya perubahan budaya buang sampah, yang ditandai belum terklasterisasinya sampah berdasarkan tempatnya.

\section{Daftar Pustaka}

Norsujianto, T. (2015). Konversi Limbah Plastik Menjadi Minyak Sebagai Bahan Bakar Energi Baru Terbarukan. Jurnal Elemen, 1(1), 05-09.

Pane, M. M. (2013). Psikologi "Hijau" (Green Psychology) sebagai Alternatif untuk Peningkatan Kesejahteraan Psikologis Masyarakat Perkotaan. Humaniora Binus, 4(1), 411-421.

Putra, H. P., \& Yuriandala, Y. (2010). Studi Pemanfaatan Sampah Plastik Menjadi Produk dan Jasa Kreatif. Jurnal Sains \& Teknologi Lingkungan, 2(1), 21-31. https://doi.org/10.20885/jstl.vol2.iss1 .art3 
Suwahyono, U., \& Tim Penulis PS, (first). (2014). Cara Cepat Buat Kompos dari Limbah. Penebar Swadaya Grup.

Wahyuningsih, W., \& Supriyo, E. (2013).

Teknologi Produksi Pupuk Organik Cair dari Limbah Sampah Rumah Tangga di Kelurahan Lempongsari, Kodya Semarang Dengan Komposer EM-4. METANA, 9(01). https://doi.org/10.14710/metana.v9i0 1.7205

Yatim, E. M., \& Mukhlis, M. (2013). Pengaruh Lindi (Leachate) Sampah Terhadap Air Sumur Penduduk Sekitar Tempat Pembuangan Akhir (TPA) Air Dingin. Jurnal Kesehatan Masyarakat Andalas, $\quad 7(2)$, 54-59. https://doi.org/10.24893/jkma.7.2.5459.2013

Budiyantoro, C.,2010, Thermoplastik dalam Industri, Teknika Media, Surakarta

Fahlevi, M.R. (2012) Sampah Plastik (http://rizafahlevi.blogspot.com/2012 /01/twit-sampah-plastik.html)

Saputra e, 2011, "Pengolahan Sampah Plastik Menjadi Bahan Bakar Minyak (BBM) Dengan Sistem Destilasi", Fakultas Teknik Universitas Sumatra Utara.

Surya U, 2013, "Analisa Kataristik Minyak Plastik Hasil Dua Kali Proses Pirolisis", Jurusan Teknik Mesin Universitas Muhammadiyah Metro.

Kumar S., Panda, A.K., dan Singh, R.K. (2011) A Review on Tertiary Recycling of High-Density Polyethylene to Fuel,
Resources, Conservation and Recycling Vol. 55 893- 910.

Riwayat Hidup Penulis Nama Penulis dengan gelar.

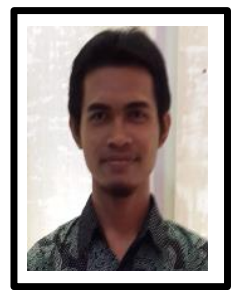

Lahir di Barito Kuala, 29 Juli 1987. Staf pengajar di Universitas Islam Kalimantan Muhammad Arsyad Al Banjari Banjarmasin. Studi S1 di Bidang Fisika Universitas Lambung Mangkurat, Banjarmasin, lulus tahun 2009; dan S2 di Bidang Fisika Material di Institut Teknologi Sepuluh Nopember, Surabaya, lulus tahun 2014. 